\title{
Solving Systems of Volterra Integral and Integrodifferential Equations with Proportional Delays by Differential Transformation Method
}

\author{
Şuayip Yüzbaşı and Nurbol Ismailov \\ Department of Mathematics, Faculty of Science, Akdeniz University, 07058 Antalya, Turkey \\ Correspondence should be addressed to Şuayip Yüzbaş1; syuzbasi@akdeniz.edu.tr
}

Received 1 May 2014; Revised 7 July 2014; Accepted 15 July 2014; Published 12 August 2014

Academic Editor: Stefan Siegmund

Copyright (C) 2014 Ş. Yüzbaşı and N. Ismailov. This is an open access article distributed under the Creative Commons Attribution License, which permits unrestricted use, distribution, and reproduction in any medium, provided the original work is properly cited.

In this paper, the differential transformation method is applied to the system of Volterra integral and integrodifferential equations with proportional delays. The method is useful for both linear and nonlinear equations. By using this method, the solutions are obtained in series forms. If the solutions of the problem can be expanded to Taylor series, then the method gives opportunity to determine the coefficients of Taylor series. Hence, the exact solution can be obtained in Taylor series form. In illustrative examples, the method is applied to a few types of systems.

\section{Introduction}

Integral and integrodifferential equations have found applications in engineering, physics, chemistry, and insurance mathematics [1-3]. In particular, functional-differential equations with proportional delays have described some models such as motion of particle in liquid and polymer crystallization which can be found in [4].

There are a lot of methods of approach for solutions of systems of integral and integrodifferential equations. For example, the linear and nonlinear systems of integrodifferential equations have been solved by Haar functions [5]; Maleknejad and Tavassoli Kajani [6] used the hybrid Legendre functions, the Chebyshev polynomial method [7], the Bessel collocation method $[8,9]$, the Taylor collocation method [10], the homotopy perturbation method [11, 12], the variational iteration method [13], the differential transformation method [14], and the Taylor series method [15]. Biazar et al. [16] have obtained the solutions of systems of Volterra integral equations of the first kind by the Adomian method. In addition, the homotopy perturbation method has been used for systems of Abel's integral equations [17]. On the other hand, the special systems of integral equations have been solved by the differential transformation method [18]. Katani and Shahmorad [19] have presented Romberg quadrature for the systems of Urysohn type Volterra integral equations. The nonlinear systems of Volterra integrodifferential equations with delay arguments have been studied by Yalçınbaş and Erdem [20].

In this paper, we consider the system of Volterra integral and integrodifferential equations with proportional delays:

$$
F_{k}\left(x, y_{k}^{(l)}\left(p_{k} x\right), \int_{0}^{r x} G_{k}\left(x, t, y_{k}\left(q_{k} t\right)\right) d t\right)=0,
$$

where $F_{k}, G_{k}$ are given functions, $p_{k}, q_{k}, r \in(0,1], k=1$, $2, \ldots, n$, and $l=0,1, \ldots, m$.

\section{Differential Transformation Method}

In 1987, the differential transformation method is introduced by Zhou [21] in the study of electric circuits. The method based on Taylor series and yields of differential transformation are difference equations which solutions give the exact values of derivatives of origin function at the given point. The method has been used for a wide class of problems [22-25]. The main advantage of differential transformation from Laplace and Fourier transformations is that it can be 
applied easily to linear equations with constant and variable coefficients and some nonlinear equations.

The differential transformation of the $k$ th derivative of function $y(x)$ is defined by

$$
Y(k)=\frac{1}{k !}\left[\frac{d^{k} y(x)}{d x^{k}}\right]_{x=x_{0}}
$$

and the inverse transformation is defined as follows:

$$
y(x)=\sum_{k=0}^{\infty} Y(k)\left(x-x_{0}\right)^{k} .
$$

(2) and (3).

The following theorems can be obtained from definitions

Theorem 1. Assume that $F(k), G(k), H(k)$ are the differential transformations, at the $x_{0}=0$, of the functions $f(x), g(x)$, $h(x)$, respectively; then one has the following.

If $f(x)=d^{n} g(x) / d x^{n}$, then $F(k)=((k+n) ! / k !) G(k+$ $n)$.

If $f(x)=g(x) h(x)$, then $F(k)=\sum_{l=0}^{k} G(l) H(k-l)$.

If $f(x)=x^{n}$, then $F(k)=\delta(k-n), \delta$ is the Kronecker delta symbol.

If $f(x)=e^{\lambda x}$, then $F(k)=\lambda^{k} / k$ !.

If $f(x)=\sin (\omega x+\lambda)$, then $F(k)=\left(\omega^{k} / k !\right) \sin (k \pi / 2+$ $\lambda)$.

If $f(x)=\cos (\omega x+\lambda)$, then $F(k)=\left(\omega^{k} / k !\right) \cos (k \pi / 2+$ $\lambda)$.

If $f(x)=g(x) \int_{0}^{x} h(t) d t$, then $F(k)=\sum_{l=0}^{k-1}(1 /(k-$ l)) $G(l) H(k-l-1)$.

Theorem 2. Assume that $W(k), Y(k)$, and $Y_{i}(k), i=1, \ldots, n$, are the differential transformations, at the $x_{0}=0$, of the functions $w(x), y(x)$, and $y_{i}(x)$, respectively, and $q, q_{i}, r \in$ $(0,1], i=1,2$. Then, one has the following.

$$
\begin{aligned}
& \text { If } w(x)=y(q x) \text {, then } W(k)=q^{k} Y(k) \text {. } \\
& \text { If } w(x)=y_{1}\left(q_{1} x\right) y_{2}\left(q_{2} x\right) \text {, then } W(k)= \\
& \sum_{l=0}^{k} q_{1}^{l} q_{2}^{k-l} Y_{1}(l) Y_{2}(k-l) \text {. } \\
& \text { If } w(x)=d^{m} y(q x) / d x^{m} \text {, then } W(k)=((k+ \\
& m) ! / k !) q^{k+m} Y(k+m) \text {. } \\
& \text { If } w(x)=\int_{0}^{r x} y(q t) d t \text {, then } W(k)=\left(r^{k} / k\right) q^{k-1} Y(k- \\
& 1) \text {. } \\
& \text { If } w(x)=\int_{0}^{x} y_{1}\left(q_{1} t\right) y_{2}\left(q_{2} t\right) d t \text {, then } W(k)= \\
& (1 / k) \sum_{l=0}^{k-1} q_{1}^{l} q_{2}^{k-l-1} Y_{1}(l) Y_{2}(k-l-1) \text {. } \\
& \text { If } w(x)=y(q x) \int_{0}^{x} y_{1}\left(q_{1} t\right) y_{2}\left(q_{2} t\right) d t \text {, then } \\
& W(k)=\sum_{l=0}^{k-1} \sum_{s=0}^{k-l-1} \frac{1}{k-l} q^{l} q_{1}^{s} q_{2}^{k-l-s-1} Y(l) \\
& \times Y_{1}(s) Y_{2}(k-l-s-1),
\end{aligned}
$$

where $k \in N$.

The proofs of Theorems 1 and 2 are given in $[22,25]$.

\section{Illustrate Examples}

Example 1. Let us consider the following linear system of Volterra integrodifferential equations with proportional delays and separable kernels:

$$
\begin{aligned}
& y_{1}(x)-y_{1}^{\prime}\left(\frac{x}{3}\right)+9 y_{2}^{\prime}\left(\frac{x}{3}\right) \\
&= 4 \cos x+8 \int_{0}^{x} \cos (x-t) y_{2}\left(\frac{t}{3}\right) d t \\
&+\frac{1}{9} \int_{0}^{x} y_{1}\left(\frac{t}{3}\right) d t \\
& y_{2}(x)+y_{1}^{\prime}(x)-4 y_{2}^{\prime}(x) \\
&=-2 \cos \frac{x}{2}-2+3 \int_{0}^{x} \sin (x-t) y_{1}\left(\frac{t}{2}\right) d t \\
&+\int_{0}^{x} y_{2}\left(\frac{t}{2}\right) d t,
\end{aligned}
$$

with the initial conditions $y_{1}(0)=1$ and $y_{2}(0)=0$.

The differential transformation of the last system is

$$
\begin{aligned}
Y_{1}(k) & -\frac{k+1}{3^{k+1}} Y_{1}(k+1)+9 \frac{k+1}{3^{k+1}} Y_{2}(k+1) \\
= & \frac{4}{k !} \cos \frac{\pi k}{2}+8 \sum_{l=0}^{k-1} \sum_{s=0}^{k-l-1} \frac{Y_{2}(k-l-s-1)}{3^{k-l-s-1}(k-l) l ! s !} \cos \left(\frac{\pi}{2}[l-s]\right) \\
& +\frac{Y_{1}(k-1)}{3^{k+1} k}, \\
Y_{2}(k) & +(k+1) Y_{1}(k+1)-4(k+1) Y_{2}(k+1) \\
= & -\frac{1}{2^{k-1} k !} \cos \frac{\pi k}{2}-2 \delta(k) \\
& +3 \sum_{l=0}^{k-1} \sum_{s=0}^{k-l-1} \frac{Y_{2}(k-l-s-1)}{2^{k-l-s-1}(k-l) l ! s !} \sin \left(\frac{\pi}{2}[l-s]\right) \\
& +\frac{Y_{2}(k-1)}{2^{k-1} k} .
\end{aligned}
$$

Substituting $x=0$ in Example 1, we obtain values of first derivatives of unknown functions; that is, $Y_{1}(1)=0$ and $Y_{2}(1)=1$.

For $k=1$ in (6), we have the following system:

$$
\begin{gathered}
Y_{1}(1)-\frac{2}{9} Y_{1}(2)+2 Y_{2}(2)=8 Y_{2}(0)+\frac{1}{9} Y_{1}(0), \\
Y_{2}(1)+2 Y_{1}(2)-8 Y_{2}(2)=Y_{2}(0) .
\end{gathered}
$$
0 . 
Substituting $k=2$ in (6), we obtain the following system of equations:

$$
\begin{aligned}
& \frac{1}{9} Y_{1}(3)-Y_{2}(3)-\frac{2}{3}=-\frac{1}{2} \\
& -3 Y_{1}(3)+12 Y_{2}(3)+2=0 .
\end{aligned}
$$

Solving the last system with two unknown, we have $Y_{1}(3)=0$ and $Y_{2}(3)=-1 / 6$.

Continue this process and use inverse transformation; we get $y_{1}(x)=\cos x$ and $y_{2}(x)=\sin x$ which are the exact solutions of Example 1.

Example 2. Consider the following system of nonlinear Volterra integrodifferential equations with proportional delays:

$$
\begin{gathered}
y_{1}(x)+y_{2}^{\prime}(x)=x-\frac{1}{4} x^{2}+\int_{0}^{x} y_{1}\left(\frac{t}{2}\right) d t \\
y_{2}(x)+y_{1}^{\prime}(x)=e^{x}-3(x-3) e^{x / 3}+\int_{0}^{x} y_{1}(t) y_{2}\left(\frac{t}{3}\right) d t
\end{gathered}
$$

with the initial conditions $y_{1}(0)=0$ and $y_{2}(0)=1$. 1.

Analogously, for $x=0$ in (9), we get $y_{1}^{\prime}(0)=1$ and $y_{2}^{\prime}(0)=$

Applying the differential transformation to (9), we have the following system of difference equations:

$$
\begin{aligned}
& Y_{1}(k)+(k+1) Y_{2}(k+1) \\
& =\frac{1}{k !}+\delta(k-1)-\frac{1}{4} \delta(k-2)+\frac{1}{k 2^{k}-1} Y_{1}(k-1), \\
& Y_{2}(k)+(k+1) Y_{1}(k+1) \\
& =\frac{1}{k !}-3 \sum_{l=0}^{k} \delta(l-1) \frac{1}{3^{k-l}(k-l) !}+\frac{1}{3^{k-2} k !} \\
& \quad+\frac{1}{k} \sum_{l=0}^{k-1} \frac{Y_{1}(l) Y_{2}(k-l-1)}{3^{k-l-1}} .
\end{aligned}
$$

For $k=1$ in (10), we get the following system:

$$
\begin{gathered}
Y_{1}(1)+2 Y_{2}(2)=2+Y_{1}(0) \\
Y_{2}(1)+2 Y_{1}(2)=1
\end{gathered}
$$

Solving the last system, we obtain $Y_{1}(2)=0$ and $Y_{2}(2)=$ $1 / 2=1 / 2$ !

Substituting $k=2$ in (10) and solving corresponding system, we have $Y_{1}(3)=0$ and $Y_{2}(3)=1 / 6=1 / 3$ !, and for $k \geq 3, Y_{1}(k)=0$ and $Y_{2}(k)=1 / k$ !. Then using (3), we gain $y_{1}(x)=x$ and $y_{2}(x)=e^{x}$ which are the exact solutions of system (9).
Example 3. Consider the following system of nonlinear Volterra integral equations:

$$
\begin{gathered}
y_{1}(x)=\frac{x^{3}}{324}+\frac{89 x^{2}}{90}-\int_{0}^{x / 3}\left[y_{1}\left(\frac{t}{2}\right)-y_{2}\left(\frac{t}{5}\right)\right] d t \\
y_{2}(x)=x+\frac{8 x^{3}}{27}+\int_{0}^{x}\left[y_{1}\left(\frac{t}{3}\right)-y_{2}^{2}(t)\right] d t
\end{gathered}
$$

with the initial condition $y_{1}(0)=y_{2}(0)=0$.

Now, applying the differential transformation to (12), we get the following system of difference equations:

$$
\begin{gathered}
Y_{1}(k)=\frac{\delta(k-3)}{324}+\frac{89 \delta(k-2)}{90}-\frac{Y_{1}(k-1)}{3^{k} 2^{k-1} k}+\frac{Y_{2}(k-1)}{3^{k} 5^{k-1} k} \\
Y_{2}(k)=\delta(k-1)+\frac{8 \delta(k-3)}{27}+\frac{Y_{1}(k-1)}{3^{k-1} k} \\
-\frac{1}{k} \sum_{l=0}^{k-1} Y_{2}(l) Y_{2}(k-l-1) .
\end{gathered}
$$

From initial conditions, we have $Y_{1}(0)=Y_{2}(0)=0$. Using (13), we get the following values:

$$
\begin{array}{ll}
Y_{1}(1)=0, & Y_{1}(2)=1, \\
Y_{2}(1)=1, & Y_{2}(2)=0,
\end{array}
$$

and for $k \geq 3, Y_{1}(k)=Y_{2}(k)=0$.

Using (3), we have $y_{1}(x)=x$ and $y_{2}(x)=x^{2}$ which are exact solutions of system (12).

Example 4. In last we consider the linear system with variable coefficients of Volterra integral equations with proportional delays:

$$
\begin{gathered}
x^{2} y_{1}\left(\frac{x}{4}\right)+2 \sin x y_{2}\left(\frac{x}{3}\right) \\
=\sin \frac{4 x}{3}+\sin \frac{2 x}{3}+2 \int_{0}^{x / 2} x y_{1}(t) d t \\
\sin \frac{x}{3} y_{1}(x)+x y_{2}\left(\frac{x}{2}\right)=x \cos \frac{x}{2}+\int_{0}^{x / 3} x y_{2}(t) d t
\end{gathered}
$$

with exact solutions $y_{1}(x)=x$ and $y_{2}(x)=\cos x$. 
Applying DTM, we have

$$
\begin{aligned}
& \sum_{l=0}^{k} \delta(l-2) Y_{1}(k-l) \frac{1}{4^{k-l}}+2 \sum_{l=0}^{k} \frac{1}{l ! 3^{k-l}} \sin \frac{l \pi}{2} Y_{2}(k-l) \\
&= \frac{4^{k}}{3^{k} k !} \sin \frac{k \pi}{2}+\frac{2^{k}}{3^{k} k !} \sin \frac{k \pi}{2} \\
&+2 \sum_{l=0}^{k} \delta(l-1) Y_{1}(k-l-1) \frac{1}{(k-l) 2^{k-l}}, \\
& \sum_{l=0}^{k} \frac{1}{l ! 3^{l}} \sin \frac{l \pi}{2} Y_{1}(k-l)+\sum_{l=0}^{k} \delta(l-1) Y_{2}(k-l) \frac{1}{2^{k-l}} \\
&=\sum_{l=0}^{k} \delta(l-1) \frac{1}{(k-l) ! 2^{k-l}} \cos \left(\frac{k-l}{2} \pi\right) \\
& \quad+\sum_{l=0}^{k-1} \delta(l-1) Y_{2}(k-l-1) \frac{1}{(k-l) 3^{k-l}} .
\end{aligned}
$$

Solving the last system we have $y_{1}(x)=x$ and $y_{2}(x)=1-$ $\left(x^{2} / 2\right)+\left(x^{4} / 4\right)-\cdots$ which are Taylor series of exact solutions of Example 4.

\section{Conclusions}

In this study, the differential transformation method has been presented for solving system of integral and integrodifferential equations with proportional delays. The major benefits of method from integral transformations are that the method can be applied for linear equations with variable coefficients and nonlinear equations and the method gives the exact solutions in series forms.

\section{Conflict of Interests}

The authors declare that there is no conflict of interests regarding the publication of this paper.

\section{Acknowledgment}

The authors would like to thank the reviewers for their constructive comments and suggestions to improve the paper.

\section{References}

[1] R. P. Agarwal, D. O’Regan, and P. J. Y. Wong, "Eigenvalues of a system of Fredholm integral equations," Mathematical and Computer Modelling, vol. 39, no. 9-10, pp. 1113-1150, 2004.

[2] R.F. Churchhouse, Handbook of Applicable Mathematics, John Wiley \& Sons, New York, NY, USA, 1981.

[3] R. P. Kanwal, Linear Integral Equations, Birkhäauser, Boston, Mass, USA, 1997.

[4] V. Kolmanovskii and A. Myshkis, Introduction to the Theory and Applications of Functional Differential Equations, Kluwer Academic Publishers, Dordrecht, The Netherlands, 1999.
[5] K. Maleknejad, F. Mirzaee, and S. Abbasbandy, "Solving linear integro-differential equations system by using rationalized Haar functions method," Applied Mathematics and Computation, vol. 155, no. 2, pp. 317-328, 2004.

[6] K. Maleknejad and M. Tavassoli Kajani, "Solving linear integrodifferential equation system by Galerkin methods with hydrid functions," Applied Mathematics and Computation, vol. 159, no. 3, pp. 603-612, 2004.

[7] A. Dascioglu and M. Sezer, "Chebyshev polynomial solutions of systems of higher-order linear Fredholm-Volterra integrodifferential equations," Journal of the Franklin Institute, vol. 342, pp. 688-701, 2005.

[8] Ş. Yüzbaşı, N. Şahin, and M.Sezer, "Numerical solutions of systems of linear Fredholm integro-differential equations with Bessel polynomial bases," Computers \& Mathematics with Applications, vol. 61, no. 10, pp. 3079-3096, 2011.

[9] N. Şahin, Ş. Yüzbaşı, and M. Gülsu, "A collocation approach for solving systems of linear Volterra integral equations with variable coefficients," Computers and Mathematics with Applications, vol. 62, no. 2, pp. 755-769, 2011.

[10] M. Gülsu and M. Sezer, "Taylor collocation method for solution of systems of high-order linear Fredholm-Volterra integrodifferential equations," International Journal of Computer Mathematics, vol. 83, no. 4, pp. 429-448, 2006.

[11] E. Yusufoğlu, "An efficient algorithm for solving integrodifferential equations system," Applied Mathematics and Computation, vol. 192, no. 1, pp. 51-55, 2007.

[12] E. Yusufoğlu, "A homotopy perturbation algorithm to solve a system of Fredholm-Volterra type integral equations," Mathematical and Computer Modelling, vol. 47, no. 11-12, pp. 1099-1107, 2008.

[13] J. Saberi-Nadjafi and M. Tamamgar, "The variational iteration method: a highly promising method for solving the system of integro-differential equations," Computers \& Mathematics with Applications, vol. 56, no. 2, pp. 346-351, 2008.

[14] A. Arikoglu and I. Ozkol, "Solutions of integral and integrodifferential equation systems by using differential transform method," Computers \& Mathematics with Applications, vol. 56, no. 9, pp. 2411-2417, 2008.

[15] H. H. Sorkun and S. Yalçinbas, "Approximate solutions of linear Volterra integral equation systems with variable coefficients," Applied Mathematical Modelling, vol. 34, no. 11, pp. 3451-3464, 2010.

[16] J. Biazar, E. Babolian, and R. M. Islam, "Solution of a system of Volterra integral equations of the first kind by Adomian method," Applied Mathematics and Computation, vol. 139, no. 2-3, pp. 249-258, 2003.

[17] S. Kumar, O. P. Singh, and S. Dixit, "Homotopy perturbation method for solving system of generalized Abel's integral equations," Applications and Applied Mathematics, vol. 6, no. 11, pp. 2009-2024, 2011.

[18] J. Biazar, M. Eslami, and M. R. Islam, "Differential transform method for special systems of integral equations," Journal of King Saud University-Science, vol. 24, no. 3, pp. 211-214, 2012.

[19] R. Katani and S. Shahmorad, "A block by block method with Romberg quadrature for the system of Urysohn type Volterra integral equations," Computational and Applied Mathematics, vol. 31, no. 1, pp. 191-203, 2012.

[20] S. Yalçınbaş and K. Erdem, "A new approximation method for the systems of nonlinear fredholm integral equations," Applied Mathematics and Physics, vol. 2, no. 2, pp. 40-48, 2014. 
[21] J. K. Zhou, Differential Transformation and Its Applications for Electrical Circuits, Huazhong University Press, Wuhan, China, 1986, (Chinese).

[22] A. Arikoglu and I. Ozkol, "Solution of boundary value problems for integro-differential equations by using differential transform method," Applied Mathematics and Computation, vol. 168, no. 2, pp. 1145-1158, 2005.

[23] F. Ayaz, "Applications of differential transform method to differential-algebraic equations," Applied Mathematics and Computation, vol. 152, no. 3, pp. 649-657, 2004.

[24] Y. Khan, Z. Svoboda, and Z. Šmarda, "Solving certain classes of Lane-Emden type equations using the differential transformation method," Advances in Difference Equations, vol. 2012, article 174, 2012.

[25] Z. Šmarda, J. Diblík, and Y. Khan, "Extension of the differential transformation method to nonlinear differential and integrodifferential equations with proportional delays," Advances in Difference Equations, vol. 2013, article 69, 2013. 


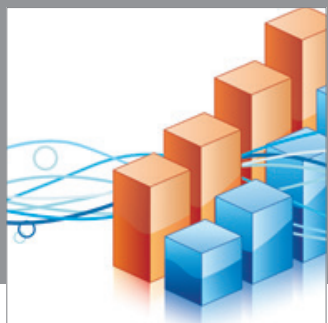

Advances in

Operations Research

mansans

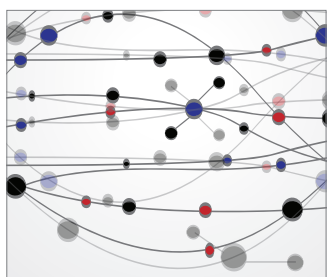

The Scientific World Journal
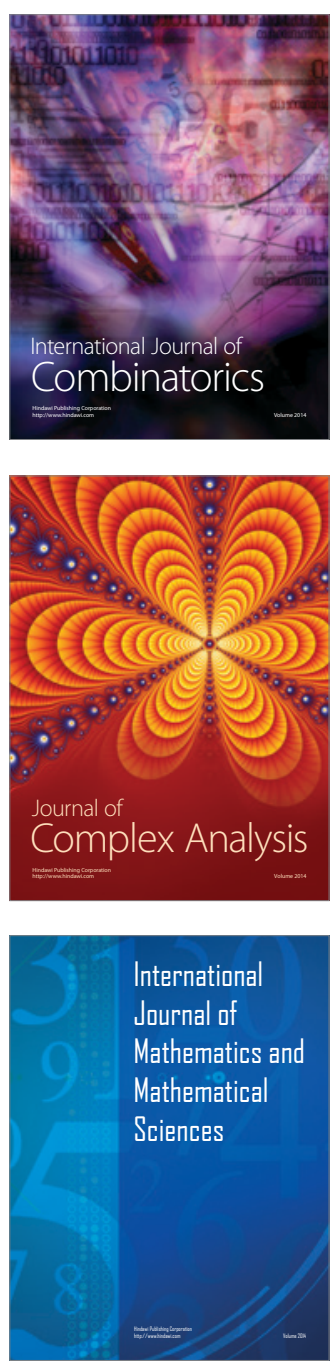
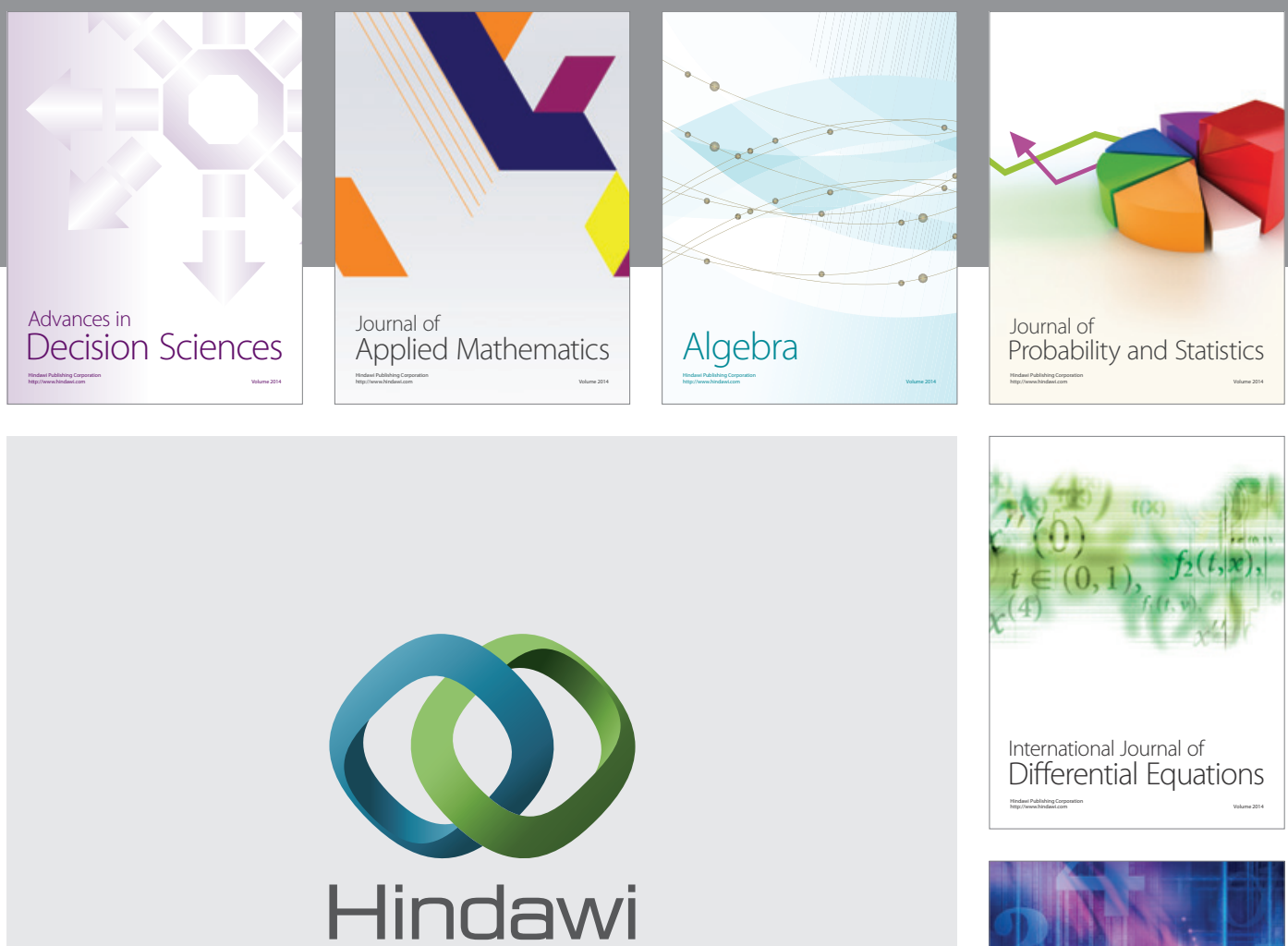

Submit your manuscripts at http://www.hindawi.com
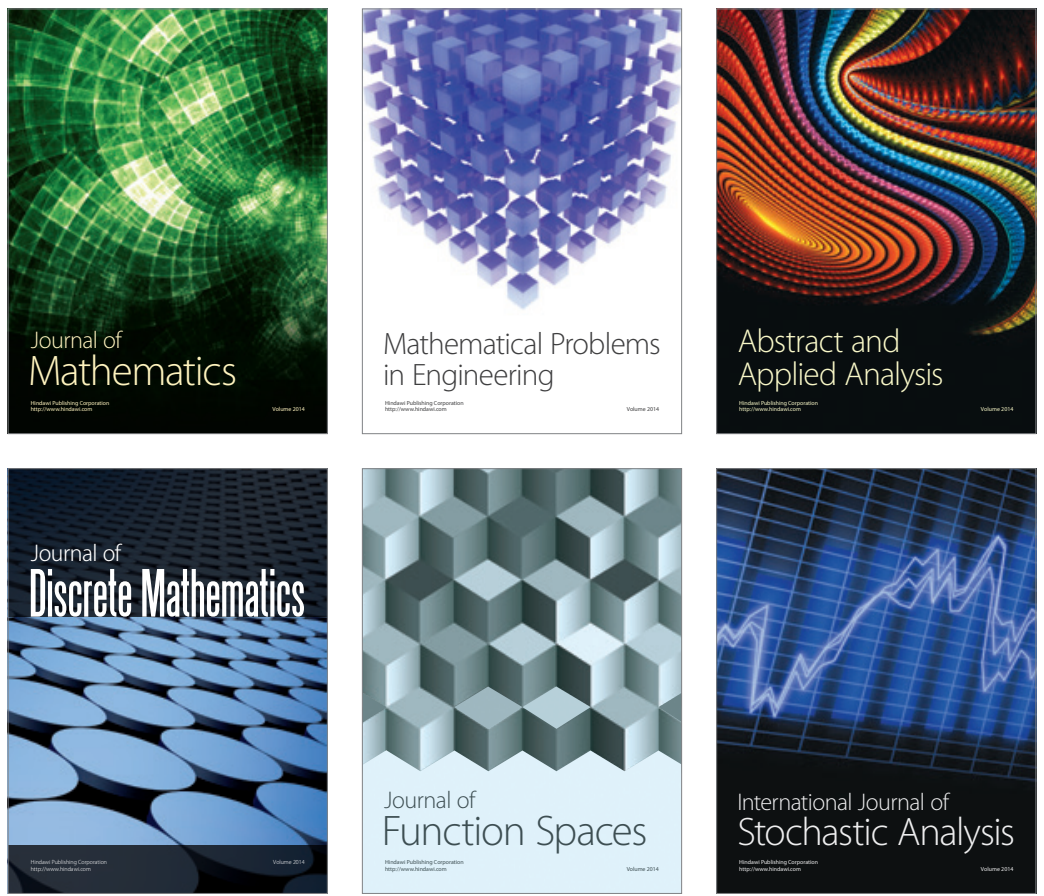

Journal of

Function Spaces

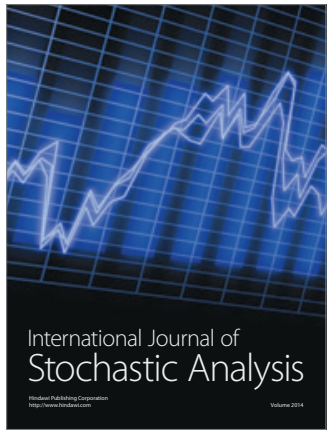

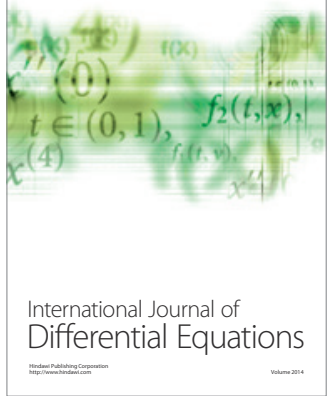
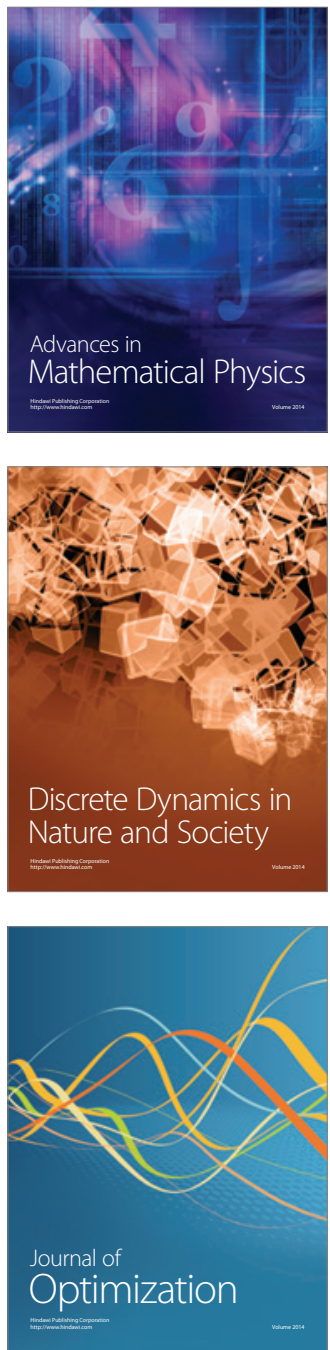